\title{
Aspirin plus Clopidogrel as Secondary Prevention after Stroke or Transient Ischemic Attack: A Systematic Review and Meta-Analysis
}

\author{
Qinghua Zhang ${ }^{\mathrm{a}}$ Chao Wang ${ }^{\mathrm{b}}$ Maoyong Zheng ${ }^{\mathrm{a}}$ Yanxia $\mathrm{Li}^{\mathrm{a}}$ Jincun $\mathrm{Li}^{\mathrm{a}}$ \\ Liping Zhang $^{\mathrm{a}}$ Xiao Shang $^{\mathrm{a}}$ Chuanzhu Yan ${ }^{\mathrm{c}}$ \\ Departments of ${ }^{\mathrm{a}}$ Neurology and ${ }^{\mathrm{b}}$ Rehabilitation, Shandong Provincial Hospital Affiliated to Shandong University, \\ and ${ }^{C}$ Department of Neurology, Qilu Hospital of Shandong University, Key Laboratory for Experimental Teratology \\ of the Ministry of Education, Brain Science Research Institute, Shandong University, Jinan, Shandong, China
}

\section{Key Words}

Stroke - Transient ischemic attack - Antiplatelet therapy ·

Secondary prevention $\cdot$ Meta-analysis

\begin{abstract}
Background: Antiplatelet agents are the mainstay for secondary prevention of non-cardioembolic stroke. This systematic review examined the safety and efficacy of short-, middle-, and long-term aspirin in combination with clopidogrel as secondary prevention of stroke or transient ischemic attack (TIA) of presumed arterial origin. Methods: PubMed, EmBase, and CENTRAL were searched up to May 2014. Randomized controlled trials (RCTs) that compared aspirin plus clopidogrel versus aspirin or clopidogrel as secondary prevention of stroke or TIA of arterial origin were included. The analyses were stratified into short-term ( $\leq 3$ months), middle-term ( $>3$ months and $<1$ year), and long-term ( $\geq 1$ year). Outcomes were compared using risk ratio (RR) and $95 \%$ confidence interval $(95 \% \mathrm{Cl})$. Results: Eight RCTs $(20,728$ patients) were included in the overall analysis. Compared with aspirin or clopidogrel alone, the complete analysis of all the data indicated that the combination therapy significantly reduced the risk of stroke recurrence $(\mathrm{RR}, 0.82 ; 95 \% \mathrm{Cl} 0.70-$ $0.96, \mathrm{p}=0.01)$ and major vascular events (RR, $0.84 ; 95 \% \mathrm{Cl}$ $0.73-0.96, p<0.01)$. But the risk of hemorrhagic stroke (RR,
\end{abstract}

1.59; 95\% Cl 1.08-2.33, $\mathrm{p}=0.02)$ and major bleeding (RR, $1.83 ; 95 \% \mathrm{Cl} 1.37-2.45, \mathrm{p}<0.01)$ was increased. No RCT studied middle-term combination therapy. The analyses were therefore stratified into only two subgroups, short- and long-term treatment. Stratified analysis of short-term treatment showed that relative to monotherapy, the drug combination reduced the risk of stroke recurrence (RR, $0.69 ; 95 \%$ $\mathrm{Cl} 0.59-0.81, \mathrm{p}<0.01)$ and did not increase the risk of hemorrhagic stroke (RR, $1.23 ; 95 \% \mathrm{Cl} 0.50-3.04, \mathrm{p}=0.65)$ and major bleeding events (RR, $2.17 ; 95 \% \mathrm{Cl} 0.18-25.71, \mathrm{p}=0.54)$. Shortterm combination therapy was associated with a significantly lower risk of major vascular events (RR, $0.70 ; 95 \% \mathrm{Cl} 0.69$ to $0.82, p<0.01$ ). Stratified analysis of long-term treatment revealed that the combination treatment did not decrease the risk of stroke recurrence (RR, $0.92 ; 95 \% \mathrm{Cl} 0.83-1.03, \mathrm{p}=$ $0.15)$, but was associated with a significantly higher risk of hemorrhagic stroke $(\mathrm{RR}, 1.67 ; 95 \% \mathrm{Cl} 1.10-2.56, \mathrm{p}=0.02)$ and major bleeding events (RR, 1.90; $95 \% \mathrm{Cl} 1.46-2.48, \mathrm{p}<0.01)$. Long-term combination therapy failed to reduce the risk of major vascular events (RR, 0.92; 95\% $\mathrm{Cl} 0.84-1.03, \mathrm{p}=0.09$ ). Conclusions: Compared with monotherapy, short-term aspirin in combination with clopidogrel is more effective as secondary prevention of stroke or TIA without increasing the risk of hemorrhagic stroke and major bleeding events. Longterm combination therapy does not reduce the risk of stroke recurrence, and is associated with increased major bleeding

\section{KARGER 125}

(c) 2014 S. Karger AG, Base

$1015-9770 / 14 / 0391-0013 \$ 39.50 / 0$ 
events. The clinical applicability of the findings of this systematic review, however, needs to be confirmed in future clinical trials.

(c) 2014 S. Karger AG, Basel

\section{Introduction}

Stroke is a leading cause of death globally [1]. Patients surviving a stroke or transient ischemic attack (TIA) are at an increased risk for subsequent stroke [2]. Without secondary prevention measures, patients after a stroke or TIA face an annual risk of $4-16 \%$ of developing serious vascular events [3-5].

Antiplatelet agents are the mainstay for secondary prevention of non-cardioembolic stroke. Aspirin, an inhibitor of cyclooxygenase hence preventing thromboxane A2 synthesis, is routinely prescribed and prevents 13 19\% of vascular events in secondary prevention trials $[3,6]$. Clopidogrel, a P2Y12-receptor antagonist, inhibits platelet aggregation synergistically with aspirin [7-9]. The Clopidogrel in High-Risk Patients with Acute Nondisabling Cerebrovascular Events (CHANCE) study showed that aspirin plus clopidogrel is more effective than aspirin alone in reducing the risk of subsequent stroke without increasing the risk of bleeding events in patients already having an episode of minor stroke or TIA [10]. It is worth noting that the results cannot be immediately applicable to patients with moderate-to-severe stroke for whom an early secondary prevention is certainly needed [11].

However, several other high-quality trials failed to show a clear benefit of aspirin plus clopidogrel as secondary prevention [12-15]. Previous guidelines did not recommend clopidogrel plus aspirin for secondary prevention of stroke or TIA [16-18]. The latest AHA/ASA guideline cautiously recommends the combination of aspirin and clopidogrel for minor ischemic stroke or TIA within $24 \mathrm{~h}$ [19]. In this systematic review, we aimed at comparing the efficacy and safety of short-, middle-, and long-term combination treatment of clopidogrel plus aspirin versus aspirin or clopidogrel alone as secondary prevention of stroke and TIA of presumed arterial origin.

\section{Methods}

We searched eligible studies using online databases including PubMed, EmBase, the Cochrane Central Register of Controlled Trials (CENTRAL) with the last search updated on May 2014. The search used the following terms and combinations: 'clopidogrel', 'aspirin' or 'acetylsalicylic acid', 'stroke' or 'cerebrovascular disor- der' or 'transient ischemic attack' or 'cerebral infarction' or 'brain ischemia'. No language or date restriction was applied. A manual examination of the references in selected articles and pertinent reviews was also performed. The search was limited to randomized clinical trials (RCTs) conducted in adult human subjects. Only published studies with full-text articles were included.

All the following criteria must be met for inclusion in the analysis: (1) study design: randomized controlled trials, (2) patients were treated with aspirin and clopidogrel versus aspirin or clopidogrel alone, and (3) patients had prior stroke or TIA of arterial origin. The exclusion criteria included: (1) an equivocal treatment allocation process; (2) statistically significant imbalance in major baseline characteristics among the study groups; (3) use of other platelet aggregation inhibitors. For studies that produced multiple publications, only the data from the most recent or most complete publication were included in the analysis.

Two independent researchers (Q.Z. and M.Z.) assessed the study quality using the Jadad scale [20], and extracted the following data: trial name, intervention dose, number of patients, age, gender distribution, stroke type, onset-to-treatment Interval, and duration of dual treatment. After the complete analysis of all the data, the analysis was stratified into two subgroups on a pre-planned basis. Long-term combination therapy was defined as treatment with aspirin and clopidogrel lasting for at least 1 year, as described earlier [21]. Middle-term combination therapy was defined as dual treatment duration between 3 months and 1 year. Short-term combination therapy was defined as dual treatment with a duration of $\leq 3$ months. The primary outcome was stroke recurrence (all types; ischemic or hemorrhagic, fatal or nonfatal). The secondary outcomes included major vascular events and major bleeding (moderate and severe bleeding). Definition of vascular events followed that in the primary studies, where TIA and ischemic stroke were mostly defined as neurologic deficit attributable to focal brain ischemia lasting for less and more than $24 \mathrm{~h}$, respectively. Ischemic stroke was typically supported by brain imaging results. Major vascular events included stroke, myocardial infarction (MI), and vascular death. If there was a disagreement, additional researchers (C.W.) reviewed the original articles, and resolved the disagreement.

The relative risk (RR) and 95\% confidence interval (95\% CI) were estimated for each study. The Q-statistics and the $\mathrm{I}^{2}$ index were used to assess the presence and quantify the extent of heterogeneity ( $\mathrm{p} \leq 0.10$ or $\mathrm{I}^{2} \geq 50 \%$ was considered significant heterogeneity). The fixed-effects model was used when there was no statistically significant heterogeneity; otherwise, the random-effects model was used. The significance of the pooled RR was determined by using a Z-test, and $\mathrm{p}<0.05$ was considered statistically significant. All tests were 2 -sided. A sensitivity analysis was performed by excluding one trial at a time, starting from those with a lower quality score, and by excluding studies using different comparator. Funnel plot method was used to screen for potential reporting bias. The data were analyzed using the Review Manager Software 5.2 (Cochrane Collaboration, Oxford, UK).

\section{Results}

Eight RCTs involving 20,728 patients fulfilled the inclusion criteria (fig. 1) [10,12-15, 22-24]. A total of 18 studies were excluded: four were excluded because they 
Fig. 1. Flow diagram of study selection.

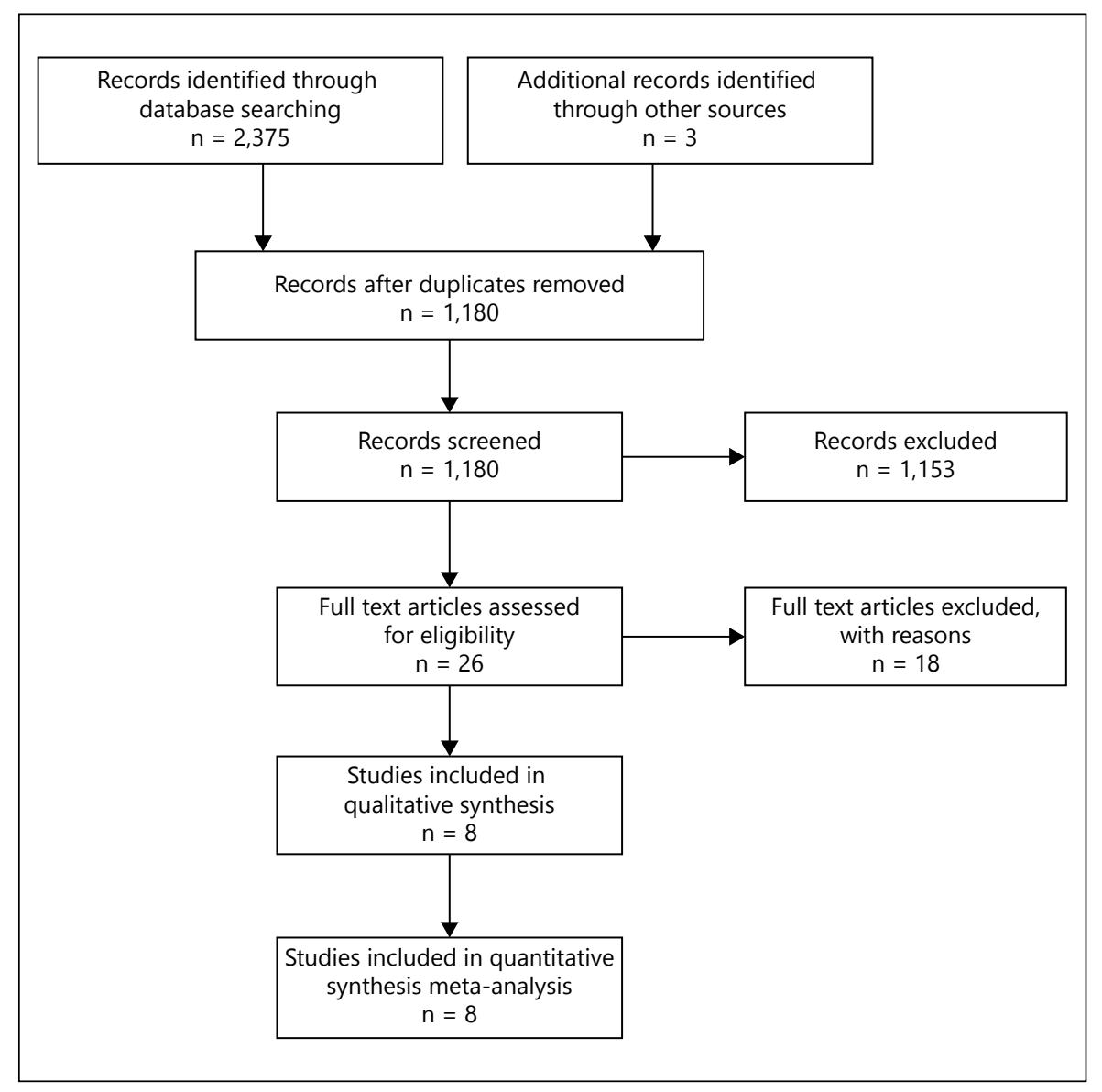

were not RCTs [25-28], three were excluded because the comparator was not aspirin or clopidogrel alone [29-31], seven were excluded for lack of specific data [9, 32-37], two were excluded since the trials were ongoing $[38,39]$, and two were excluded due to redundancy $[40,41]$ : the original study reported both primary and secondary prevention, and the subsequent report [14] focused on results in patients with previous TIA or ischemic stroke. The baseline characteristics of included studies are summarized in table 1. In the Bal Dit Sollier study [22], there were four groups, and only patients with stroke or TIA from the aspirin plus clopidogrel group and the aspirin group were included in this analysis. The Management of Atherothrombosis with Clopidogrel in High-risk patients $(\mathrm{MATCH})$ trial used clopidogrel as a comparator. The remaining 6 trials used aspirin as a comparator. For the Secondary Prevention of Small Subcortical Strokes (SPS3) study, the precise data about the incidence of hemorrhagic stroke (primary intracerebral hemorrhages) were obtained from a meta-analysis co-authored by the principal investigators of the SPS3 trial [42]. The follow-up of these studies ranged from 7 days to 3.4 years. The duration of the combination therapy was 7 days to 3 months in 5 trials [10, 13, 22-24], and more than 1 year in the remaining 3 trials $[12,14,15]$. No RCT studied middle-term combination therapy between 3 months and 1 year. The analyses were therefore only stratified into two subgroups, short- and long-term combination therapy.

\section{Stroke Recurrence}

Compared with aspirin or clopidogrel alone, data pooled from all eight trials indicated that the combination of aspirin and clopidogrel was associated with a significantly lower risk of stroke recurrence of all types (RR, 0.82 ; 95\% CI 0.70-0.96, $\mathrm{p}=0.01$ ) (fig. 2). There was a significant statistical heterogeneity $\left(\mathrm{p}=0.08, \mathrm{I}^{2}=45.0 \%\right)$. With respect to reduction of ischemic stroke (both fatal and nonfatal), there was a significant trend in favor of aspirin and clopidogrel (RR, 0.80; 95\% CI 0.73-0.88, p < 0.01 ) (fig. 3). However, the risk of hemorrhagic stroke was significantly increased in combination therapy $(R R, 1.59$; 95\% CI 1.08-2.33, $\mathrm{p}=0.02$ ) (fig. 4). 


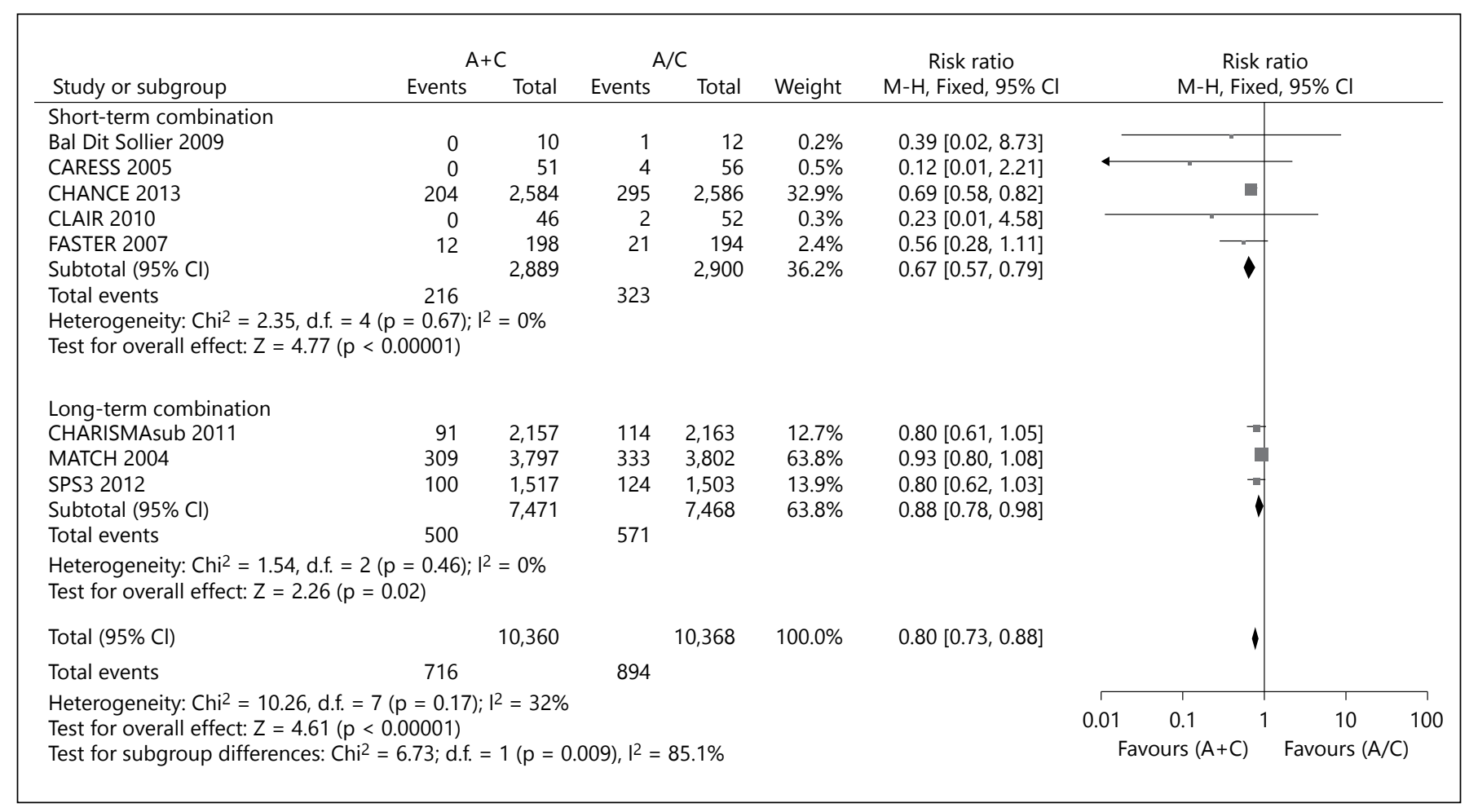

Fig. 2. Comparison of aspirin and clopidogrel versus aspirin or clopidogrel alone on stroke.

Table 1. Characteristics of included trials

\begin{tabular}{|c|c|c|c|c|c|c|c|c|c|}
\hline $\begin{array}{l}\text { Bal Dit Sollier } \\
2009\end{array}$ & A $325 \mathrm{mg}+$ C $75 \mathrm{mg}$ & A $300 \mathrm{mg}$ & 22 & 69 & 27.3 & stroke, TIA & $>8$ days & 10 days & 3 \\
\hline CARESS 2005 & A $75 \mathrm{mg}+\mathrm{C} 75 \mathrm{mg}$ & A $75 \mathrm{mg}$ & 107 & 65 & 30.8 & stroke, TIA & $<5$ months & 7 days & 5 \\
\hline $\begin{array}{l}\text { CHARISMA } \\
2011\end{array}$ & $\begin{array}{l}\text { A } 75-100 \mathrm{mg}+ \\
\text { C } 75 \mathrm{mg}\end{array}$ & A $75-100 \mathrm{mg}$ & 1,331 & 65 & 36.8 & stroke, TIA & $<5$ years & 2.1 years & 5 \\
\hline CLAIR 2010 & $\begin{array}{l}\text { A } 75-160 \mathrm{mg}+ \\
\text { C } 75 \mathrm{mg}\end{array}$ & A $75-160 \mathrm{mg}$ & 98 & 58 & 22.4 & stroke, TIA & $<7$ days & 7 days & 5 \\
\hline MATCH 2004 & A $75 \mathrm{mg}+\mathrm{C} 75 \mathrm{mg}$ & C $75 \mathrm{mg}$ & 7,599 & 66 & 37.1 & stroke, TIA & $<3$ months & 1.5 years & 5 \\
\hline SPS3 2012 & A $325 \mathrm{mg}+$ C $75 \mathrm{mg}$ & A $325 \mathrm{mg}$ & 3,020 & 63 & 37 & lacunar stroke & $<180$ days & 3.4 years & 5 \\
\hline
\end{tabular}




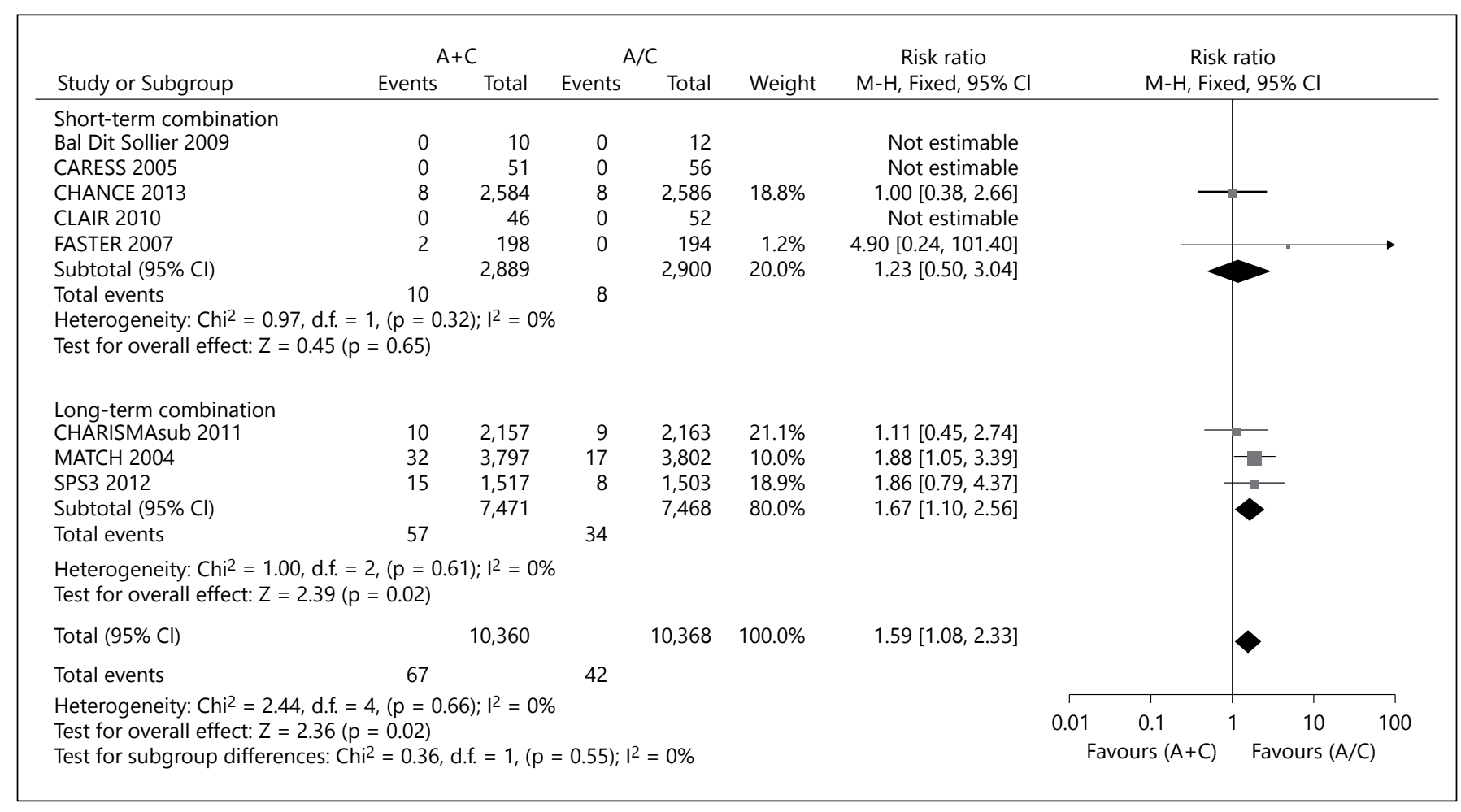

Fig. 3. Comparison of aspirin and clopidogrel versus aspirin or clopidogrel alone on ischemic stroke.

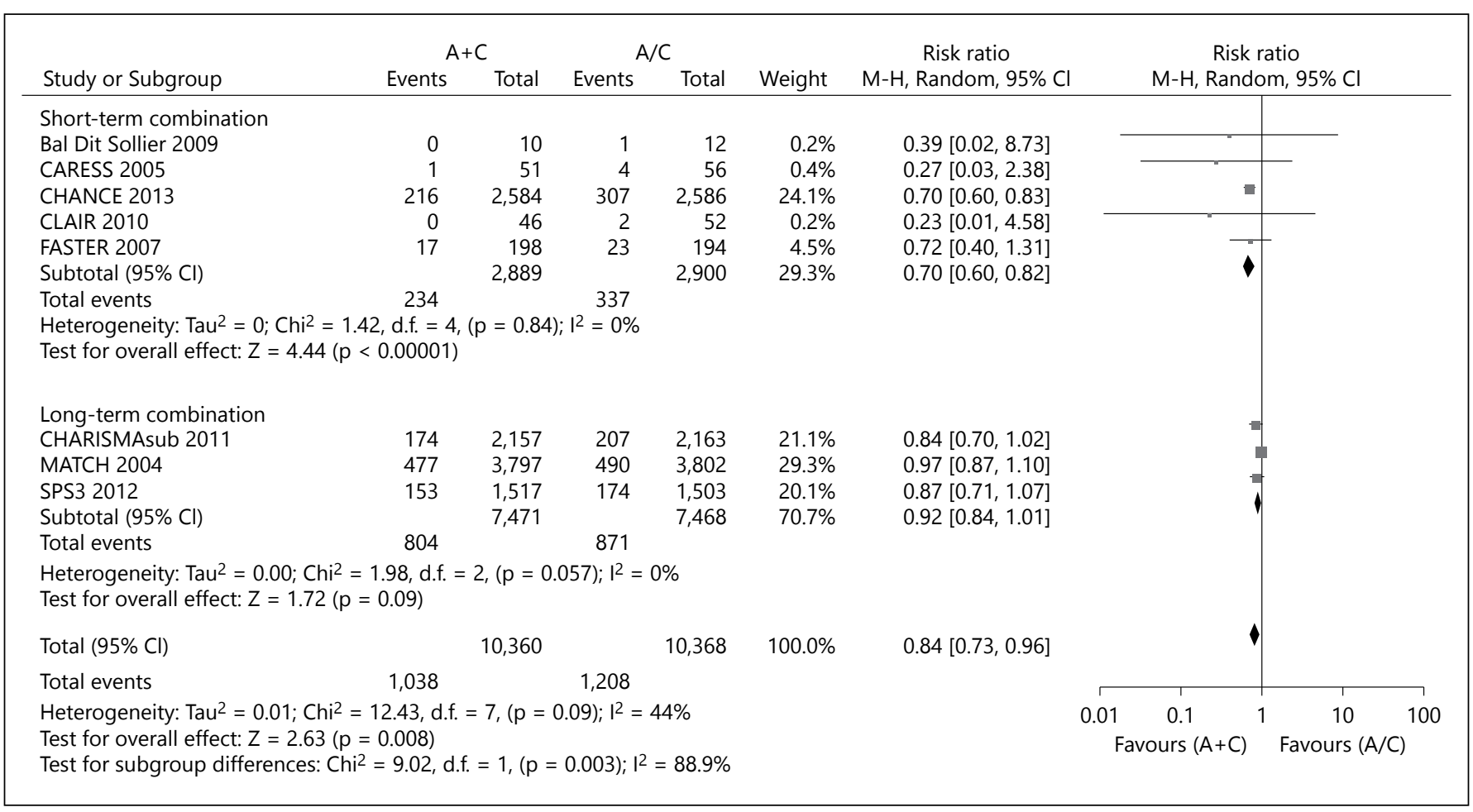

Fig. 4. Comparison of aspirin and clopidogrel versus aspirin or clopidogrel alone on hemorrhagic stroke.

Aspirin Plus Clopidogrel for Stroke or TIA
Cerebrovasc Dis 2015;39:13-22 DOI: $10.1159 / 000369778$ 


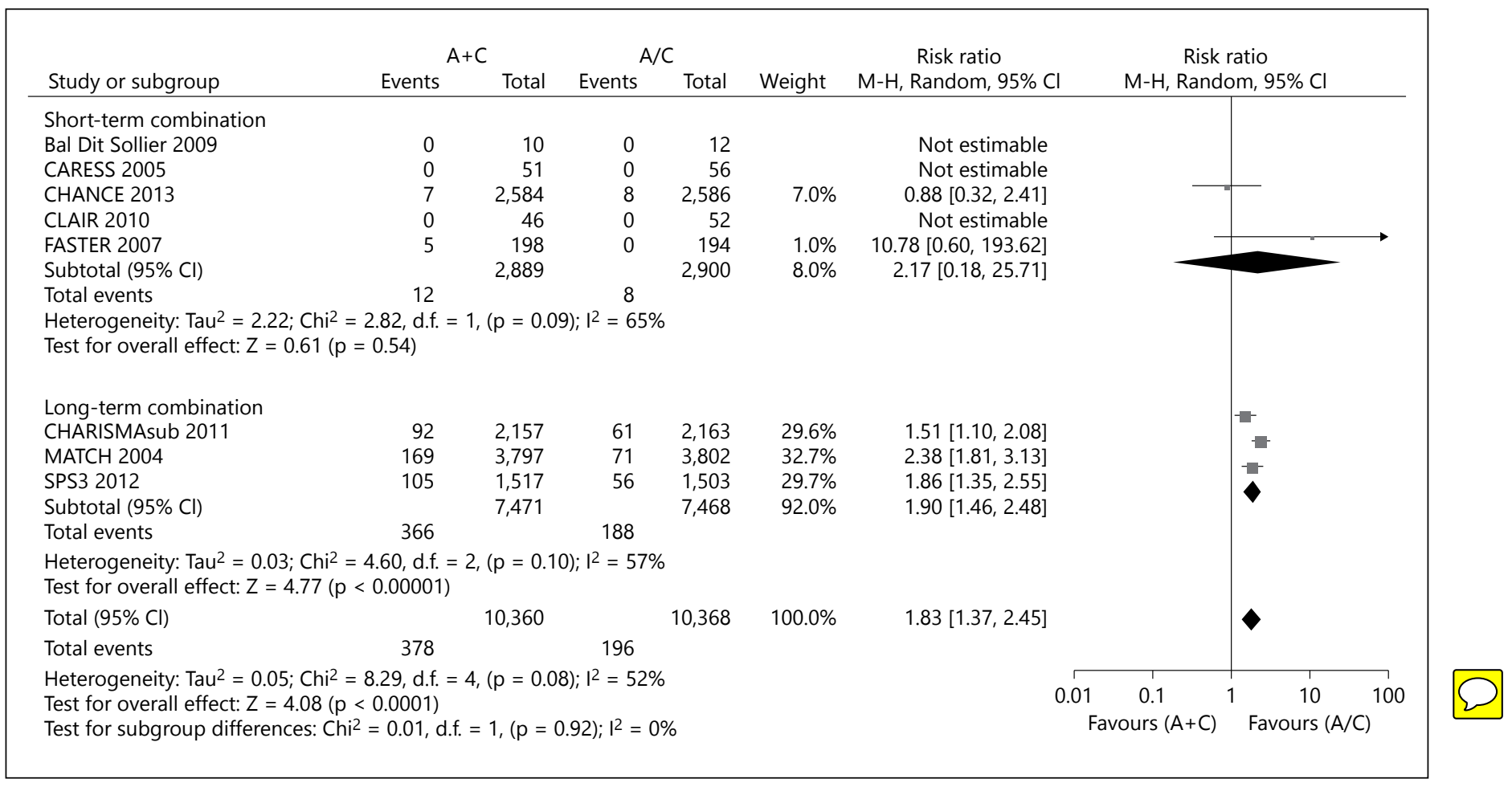

Fig. 5. Comparison of aspirin and clopidogrel versus aspirin or clopidogrel alone on stroke, MI, or vascular death.

The stratified analysis of short-term combination therapy included 5 RCTs, and revealed that, compared with aspirin monotherapy, combination therapy significantly decreased the risk of stroke recurrence (RR, 0.69; 95\% CI $0.59-0.81, \mathrm{p}<0.01$ ) (fig. 2). The combination therapy also reduced the risk of ischemic stroke (RR, 0.67; 95\% CI $0.57-0.79, \mathrm{p}<0.01$ ) (fig. 3). Hemorrhagic stroke was not affected (RR, 1.23; 95\% CI 0.50-3.04, $\mathrm{p}=0.65$ ) (fig. 4).

The stratified analysis of long-term combination therapy, which included 3 RCTs, failed to show significant reduction in stroke recurrence with combination therapy (RR, 0.92; 95\% CI 0.83-1.03, $\mathrm{p}=0.15$ ) (fig. 2). The risk for ischemic stroke, however, was lower in patients receiving combination therapy (RR, 0.88 ; 95\% CI 0.78-0.98, p = 0.02 ) (fig. 3). Additionally, there was a significantly higher risk of hemorrhagic stroke (RR, 1.67; 95\% CI 1.10-2.56, $\mathrm{p}=0.02$ ) (fig. 4). There was no significant difference in heterogeneity in any of the aforementioned stratified analysis $\left(\mathrm{p}>0.10, \mathrm{I}^{2}<50 \%\right)$.

\section{Secondary Outcomes}

Available data from 8 studies indicated a significant reduction in major vascular events during follow up (RR, 0.84; 95\% CI 0.73-0.96, $\mathrm{p}<0.01$ ) (fig. 5). The incidence of major bleeding was significantly higher in patients receiving clopidogrel plus aspirin than those receiving aspirin alone (RR, 1.83; 95\% CI 1.37-2.45, $\mathrm{p}<0.01$ ) (fig. 6). There was a significant difference in heterogeneity in major vascular events $\left(\mathrm{p}=0.09, \mathrm{I}^{2}=44 \%\right)$ and major bleeding $\left(\mathrm{p}=0.08, \mathrm{I}^{2}=52 \%\right)$.

Compared with aspirin alone, short-term combination therapy was associated with a significantly lower risk of major vascular events (RR, 0.70; 95\% CI 0.60$0.82, \mathrm{p}<0.01$ ) (fig. 5). There was no significant difference in heterogeneity $\left(\mathrm{p}=0.84, \mathrm{I}^{2}=0\right)$. The analysis did not identify significant difference in major bleeding ( $\mathrm{RR}, 2.17$; 95\% CI 0.18-25.71, $\mathrm{p}=0.54$ ) (fig. 5). A significant heterogeneity was observed $\left(\mathrm{p}=0.09, \mathrm{I}^{2}=\right.$ $65 \%)$.

The stratified analysis of the long-term combination therapy failed to reveal significant difference in major vascular events ( $R R, 0.92 ; 95 \%$ CI $0.84-1.03, \mathrm{p}=0.09$ ) (fig. 5). There was no significant difference in heterogeneity $\left(\mathrm{p}=0.37, \mathrm{I}^{2}=0\right)$. The analysis revealed a higher incidence of major bleeding upon long-term dual therapy (RR, 1.90; 95\% CI 1.46-2.48, p < 0.01) (fig. 6). There was a significant difference in heterogeneity in major bleeding $\left(\mathrm{p}=0.1, \mathrm{I}^{2}=57 \%\right)$. However, exclusion of the MATCH 


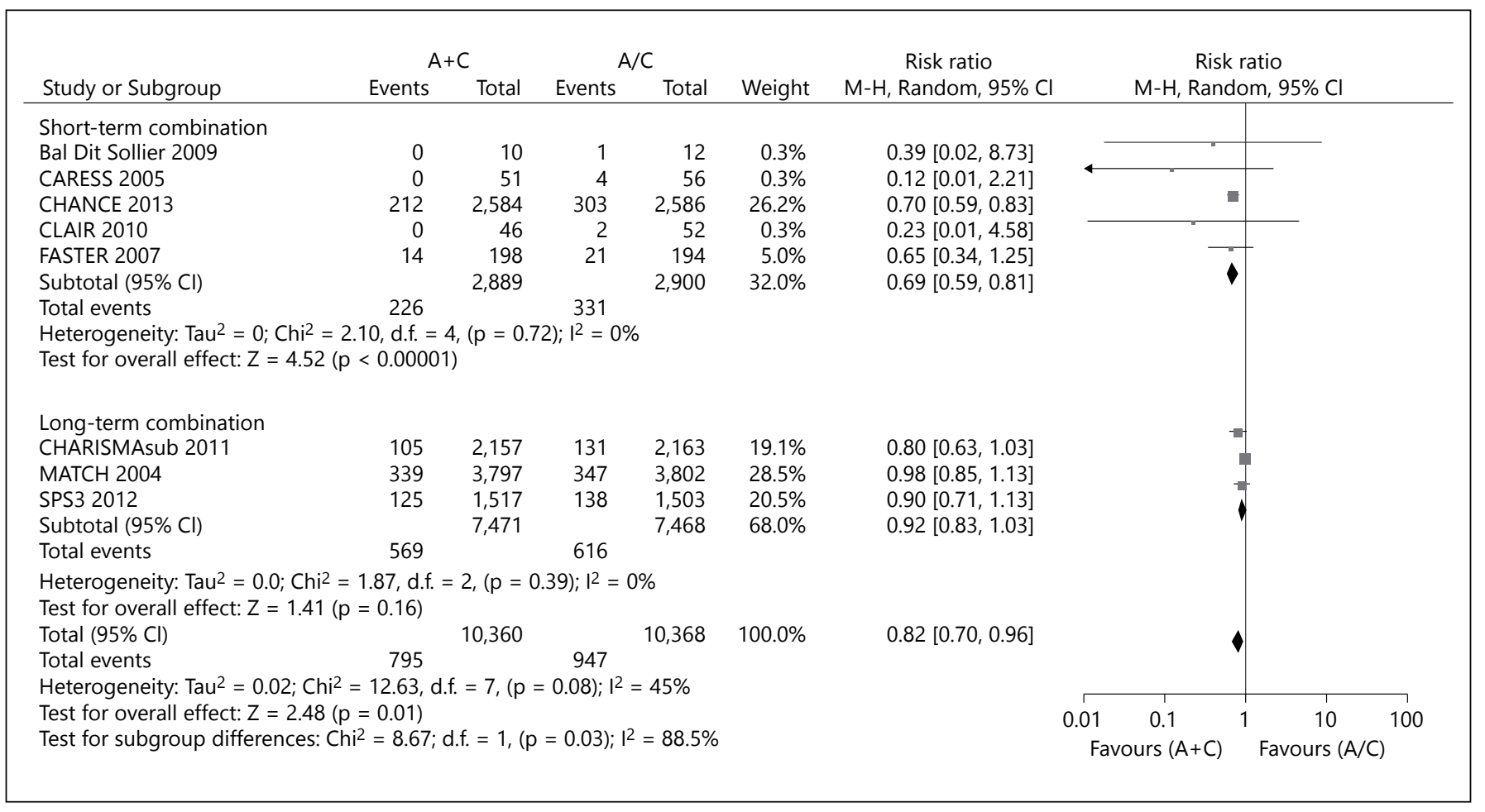

Fig. 6. Comparison of aspirin and clopidogrel versus aspirin or clopidogrel alone on major bleeding.

trial (using clopidogrel as the comparator) did not change the conclusion with regards to major bleeding (RR, 1.68; $95 \%$ CI $1.34-2.10, \mathrm{p}<0.01)$ and there was no heterogeneity $\left(\mathrm{p}=0.37, \mathrm{I}^{2}=0\right)$.

Visual inspection of funnel plots indicated an asymmetry in main outcomes (fig. 7). The Bal Dit Sollier study was of relatively low quality and small sample size. We therefore conducted a sensitivity analysis by excluding this study, which did not change the conclusion.

\section{Discussion}

The current study included eight RCTs involving 20,728 patients. The complete analysis of all the pooled data showed aspirin plus clopidogrel could significantly reduce the risk of overall stroke (regardless of stroke type) and major vascular events. However, the risk of hemorrhagic stroke and major bleeding was significantly increased in combination therapy. A stratified analysis of short-term combination therapy ( $\leq 3$ months) indicated that compared to aspirin alone, aspirin plus clopidogrel could significantly reduce the risk of stroke recurrence and major vascular events.

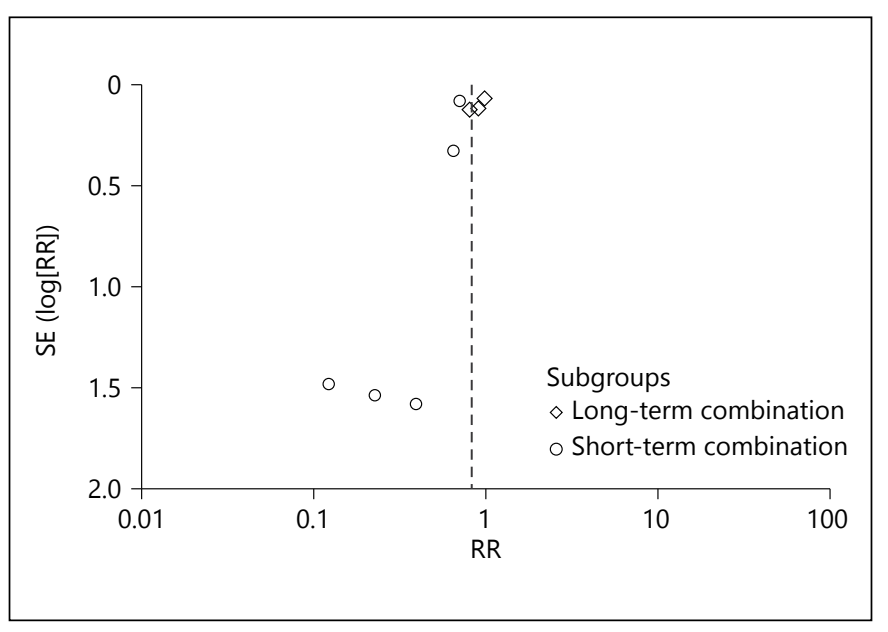

Fig. 7. Funnel plot of included studies for stroke.

The combination therapy did not increase the risk of hemorrhagic stroke and major bleeding. In the stratified analysis of long-term combination therapy $(\geq 1$ year), the combination therapy did not affect stroke recurrence and major vascular events, but increased the risk of hemorrhagic stroke and major bleeding. These 
findings are generally consistent with recent systematic reviews $[21,42,43]$.

The benefit of platelet aggregation inhibitors as secondary prevention of non-cardiogenic stroke or TIA has been well established. Recent systematic reviews indicated that early combination antiplatelet therapy is more effective in reducing the risk of stroke in patients with acute stroke or TIA compared with monotherapy $[44,45]$. Dipyridamole plus aspirin reduces the risk of stroke recurrence [46], and is recommended by major guidelines for secondary prevention of stroke in patients with stroke or TIA $[16,17,19]$.

The MATCH, SPS3 and CHARISMA (Clopidogrel for High Atherothrombotic Risk and Ischemic Stabilization, Management, and Avoidance) trials indicated that longterm therapy with aspirin plus clopidogrel is not effective in secondary prevention of stroke in patients with TIA and ischemic stroke $[12,14,15]$. The SPS3 trial examined dual treatment with aspirin $(325 \mathrm{mg} /$ day $)$ and clopidogrel $(75 \mathrm{mg} /$ day) in patients with subcortical lacunar ischemic stroke [15], and failed to show significant reduction in the risk of stroke recurrence, and was terminated due to an increased rate of major hemorrhage. Arguably, whether the dose of aspirin ( $325 \mathrm{mg} /$ day) is appropriate for longterm treatment remains an issue. All patients in SPS3 and most patients in MATCH had lacunar infarcts, which are generally considered to result from hyaline arteriolosclerosis and endothelial dysfunction in small penetrating cerebral arteries [26, 47, 48]. The use of antiplatelet therapy in patients with subcortical lacunar ischemic stroke, therefore, is theoretically problematic. In the MATCH trial, the Kaplan-Meier survival curves showed that the risk of intracranial hemorrhage for each treatment group did not diverge until at 3-4 months after randomization, with a noticeably increased risk of intracerebral hemorrhage for the combination therapy. Therefore, the use of the combination therapy beyond three months may incur an increased risk of intracerebral bleeding.

The FASTER (Fast Assessment of Stroke and TIA to prevent Early Recurrence) trial was conducted in patients with ischemic stroke or TIA within $24 \mathrm{~h}$ of symptom onset, and failed to show significant reduction in the risk of recurrent stoke and major vascular events in the dual antiplatelet group [13]. The CLAIR (clopidogrel plus aspirin versus aspirin alone for reducing embolisation in patients with acute symptomatic cerebral or carotid artery stenosis) and CARESS (Clopidogrel and Aspirin for Reduction of Emboli in Symptomatic Carotid Stenosis) trials included patients with large artery stenosis, and suggested that the combination therapy of aspirin plus clopidogrel is more effective in reducing embolization than aspirin alone [23, 24].

Stratified analysis of short-term combination therapy has revealed that the CHANCE is the only properly powered study. The CHANCE trial showed that the shortterm combination therapy reduced the risk of stroke without increasing the risk of bleeding events [10]. The CHANCE trial enrolled patients in the first $24 \mathrm{~h}$ after a minor stroke or TIA. The trial used a short course (21 days) of combined aspirin and clopidogrel, and therefore was likely to generate more apparent benefit. The trial was conducted entirely in China, where the level of healthcare, secondary prevention practices, and distribution of stroke subtypes differ from those of other countries. In addition, Chinese patients show distinct vascular pathology from Caucasian patients and thus the conclusions from the CHANCE may not be immediately applicable to Caucasian patients or patients of other ethnic descents. Patients in the CHANCE were also younger compared to the average stroke population and had less severe neurological deficits. Therefore, caution is advised when the CHANCE data is used for older patients with worse deficits who may not benefit from dual antiplatelet therapy because of the increased occurrence of hemorrhagic complications.

The meta-analysis in the current study is based on group data and not individual patient data, and is thus limited in many aspects, including the time from the event, blood pressure control, time on treatment, and stroke etiology. Furthermore, the included studies vary in terms of study sample, onset-to-treatment interval, stroke type, treatment course, comparator, and flow-up duration. Moreover, only published data were included, which may lead to a reporting bias by overestimating the effect of dual therapy. Our visual inspection of the funnel plots revealed an asymmetry, which indicates the likelihood of publication bias. The asymmetry of funnel plot may be also due to an insufficient number of trials, small-study effect and significant statistical heterogeneity. Obtaining and including data from unpublished trials may offer a way to avoid such bias, but it would be a very challenging endeavor to gain access to data from unpublished studies. In addition, the data from the CHARISMA were derived from a subgroup of patients with stroke, and thus may introduce random error.

In conclusion, the current study showed that the dual antiplatelet therapy with aspirin and clopidogrel reduces the risk of stroke recurrence and major vascular events, but increases the risk of hemorrhagic stroke and major bleeding. Short-term combination therapy ( $\leq 3$ months) 
offers protection against stroke recurrence and major vascular events without increasing the risk of hemorrhagic stroke and major bleeding events in patients with prior stroke or TIA of arterial origin. Long-term combination therapy ( $\geq 1$ year), on the other hand, does not reduce the risk of stroke recurrence and major vascular events, and is associated with increased hemorrhagic stroke and major bleeding events. This systematic review suggests the benefit of dual antiplatelet with aspirin and clopidogrel may be greatest in the short term for secondary prevention of non-cardioembolic ischemic stroke or TIA. The opinion is similar to the recommendations of the new guideline for the prevention of stroke and TIA from the AHA/ASA [19]. Further well-designed, longer follow-up clinical trials are needed to confirm possible short-term beneficial effects of aspirin plus clopidogrel as secondary prevention in non-Chinese patients with stroke and TIA. The results from long-term follow-up of CHANCE, ongoing POINT (Platelet-Oriented Inhibition in New TIA and Minor Ischemic Stroke) [39] and COMPRESS (Combination of Clopidogrel and Aspirin for Prevention of Early Recurrence in Acute Atherothrombotic Stroke) [38] trials may provide more conclusive evidence on the use of dual antiplatelet therapy for stroke patients of other ethnic descents than Chinese and for elderly stroke patients.

\section{Acknowledgments}

The research was partly supported by Shandong Provincial Natural Science Foundation, China (Y2008C2) and Shandong Provincial Medical and Health Science and Technological Program (2013ws0123), Shandong, China.

\section{Disclosure Statement}

None.

\section{References}

1 Mathers CD, Loncar D: Projections of global mortality and burden of disease from 2002 to 2030. PLoS Med 2006;3:e442.

$\checkmark 2$ Boysen G, Truelsen T: Prevention of recur rent stroke. Neurol Sci 2000;21:67-72.

-3 Algra A, van Gijn J: Aspirin at any dose above $30 \mathrm{mg}$ offers only modest protection after cerebral ischaemia. J Neurol Neurosurg Psychiatry 1996;60:197-199.

44 Antithrombotic Trialists' Collaboration: Collaborative meta-analysis of randomised trials of antiplatelet therapy for prevention of death, myocardial infarction, and stroke in high risk patients. BMJ 2002;324:71-86.

$\checkmark 5$ Warlow C: Secondary prevention of stroke. Lancet 1992;339:724-727.

-6 Antithrombotic Trialists' Collaboration: Aspirin in the primary and secondary prevention of vascular disease: collaborative meta-analysis of individual participant data from randomised trials. Lancet 2009;373:1849-1860.

-7 Herbert JM, Dol F, Bernat A, Falotico R, Lale A, Savi P: The antiaggregating and antithrombotic activity of clopidogrel is potentiated by aspirin in several experimental models in the rabbit. Thromb Haemost 1998;80:512-518.

-8 Makkar RR, Eigler NL, Kaul S, Frimerman A, Nakamura M, Shah PK, et al: Effects of clopidogrel, aspirin and combined therapy in a porcine ex vivo model of high-shear induced stent thrombosis. Eur Heart J 1998;19:1538-1546.

-9 Serebruany VL, Malinin AI, Ziai W, Pokov AN, Bhatt DL, Alberts MJ, et al: Effects of clopidogrel and aspirin in combination versus aspirin alone on platelet activation and major receptor expression in patients after re- cent ischemic stroke: for the Plavix Use for Treatment of Stroke (PLUTO-Stroke) trial. Stroke 2005;36:2289-2292.

10 Wang Y, Wang Y, Zhao X, Liu L, Wang D, Wang $\mathrm{C}$, et al: Clopidogrel with aspirin in acute minor stroke or transient ischemic attack. N Engl J Med 2013;369:11-19.

11 Hankey GJ: Dual antiplatelet therapy in acute transient ischemic attack and minor stroke. N Engl J Med 2013;369:82-83.

12 Diener HC, Bogousslavsky J, Brass LM, Cimminiello C, Csiba L, Kaste M, et al: Aspirin and clopidogrel compared with clopidogrel alone after recent ischaemic stroke or transient ischaemic attack in high-risk patients $(\mathrm{MATCH})$ : randomised, double-blind, placebo-controlled trial. Lancet 2004;364:331-337.

13 Kennedy J, Hill MD, Ryckborst KJ, Eliasziw M, Demchuk AM, Buchan AM; FASTER Investigators: Fast assessment of stroke and transient ischaemic attack to prevent early recurrence (FASTER): a randomised controlled pilot trial. Lancet Neurol 2007;6:961-969.

14 Hankey GJ, Johnston SC, Easton JD, Hacke W, Mas JL, Brennan D, et al: Effect of clopidogrel plus ASA vs. ASA early after TIA and ischaemic stroke: a substudy of the CHARISMA trial. Int J Stroke 2011;6:3-9.

15 SPS3 Investigators; Benavente OR, Hart RG, McClure LA, Szychowski JM, Coffey CS, et al: Effects of clopidogrel added to aspirin in patients with recent lacunar stroke. N Engl J Med 2012;367:817-825.

16 European Stroke Organisation (ESO) Executive Committee; ESO Writing Committee: Guidelines for management of ischaemic stroke and transient ischaemic attack 2008. Cerebrovasc Dis 2008;25:457-507.

17 Wang YJ, Zhang SM, Zhang L, Wang CX: Chinese guidelines for the secondary prevention of ischemic stroke and transient ischemic attack 2010. CNS Neurosci Ther 2012;18:93-101.

18 Kern R, Nagayama M, Toyoda K, Steiner T, Hennerici MG, Shinohara Y: Comparison of the European and Japanese guidelines for the management of ischemic stroke. Cerebrovasc Dis 2013;35:402-418.

19 Kernan WN, Ovbiagele B, Black HR, Bravata DM, Chimowitz MI, Ezekowitz MD, et al: Guidelines for the prevention of stroke in patients with stroke and transient ischemic attack: a guideline for healthcare professionals from the American Heart Association/American Stroke Association. Stroke 2014;45:2160-2236.

- 20 Jadad AR, Moore RA, Carroll D, Jenkinson C, Reynolds DJ, Gavaghan DJ, et al: Assessing the quality of reports of randomized clinical trials: is blinding necessary? Control Clin Trials 1996; 17:1-12.

21 Lee M, Saver JL, Hong KS, Rao NM, Wu YL, Ovbiagele B: Risk-benefit profile of long-term dual-versus single-antiplatelet therapy among patients with ischemic stroke: a systematic review and meta-analysis. Ann Intern Med 2013;159:463-470.

22 Bal Dit Sollier C, Crassard I, Simoneau G, Bergmann JF, Bousser MG, Drouet L: Effect of the thromboxane prostaglandin receptor antagonist terutroban on arterial thrombogenesis after repeated administration in patients treated for the prevention of ischemic stroke. Cerebrovasc Dis 2009;28:505-513. 
-23 Markus HS, Droste DW, Kaps M, Larrue V, Lees KR, Siebler M, et al: Dual antiplatelet therapy with clopidogrel and aspirin in symptomatic carotid stenosis evaluated using doppler embolic signal detection: the Clopidogrel and Aspirin for Reduction of Emboli in Symptomatic Carotid Stenosis (CARESS) trial. Circulation 2005;111:2233-2240.

24 Wong KS, Chen C, Fu J, Chang HM, Suwanwela NC, Huang YN, et al: Clopidogrel plus aspirin versus aspirin alone for reducing embolisation in patients with acute symptomatic cerebral or carotid artery stenosis (CLAIR study): a randomised, open-label, blindedendpoint trial. Lancet Neurol 2010;9:489-497.

25 Benavente OR, White CL, Pearce L, Pergola P, Roldan A, Benavente MF, et al: The Secondary Prevention of Small Subcortical Strokes (SPS3) study. Int J Stroke 2011;6:164-175.

-26 Diener HC, Weber R: Clopidogrel added to aspirin adds no benefit but bleeding risk in patients with recent lacunar stroke. Stroke 2013;44:861-863.

-27 Wang Y, Johnston SC; CHANCE Investigators: Rationale and design of a randomized, double-blind trial comparing the effects of a 3 -month clopidogrel-aspirin regimen versus aspirin alone for the treatment of high-risk patients with acute nondisabling cerebrovascular event. Am Heart J 2010;160:380-386.e1.

$\checkmark 28$ Meyer DM, Albright KC, Allison TA, Grotta JC: LOAD: a pilot study of the safety of loading of aspirin and clopidogrel in acute ischemic stroke and transient ischemic attack. J Stroke Cerebrovasc Dis 2008;17:26-29.

-29 Chimowitz MI, Lynn MJ, Derdeyn CP, Turan TN, Fiorella D, Lane BF, et al: Stenting versus aggressive medical therapy for intracranial arterial stenosis. N Engl J Med 2011;365:9931003.

-30 King A, Bath PM, Markus HS: Clopidogrel versus dipyridamole in addition to aspirin in reducing embolization detected with ambulatory transcranial Doppler: a randomized trial. Stroke 2011;42:650-655.

- 31 Kwon SU, Hong KS, Kang DW, Park JM, Lee $\mathrm{JH}, \mathrm{Cho} \mathrm{YJ}$, et al: Efficacy and safety of combination antiplatelet therapies in patients with symptomatic intracranial atherosclerotic stenosis. Stroke 2011;42:2883-2890.
32 Grau AJ, Reiners S, Lichy C, Buggle F, Ruf A: Platelet function under aspirin, clopidogrel, and both after ischemic stroke: a case-crossover study. Stroke 2003;34:849-854.

33 Helgason CM, Grossi E, Pandey D, Valika A, Cursio J, Brace LD: Platelet aggregation and recruitment with aspirin-clopidogrel therapy. Cerebrovasc Dis 2008;25:392-400.

34 Payne DA, Jones CI, Hayes PD, Thompson MM, London NJ, Bell PR, et al: Beneficial effects of clopidogrel combined with aspirin in reducing cerebral emboli in patients undergoing carotid endarterectomy. Circulation 2004; 109:1476-1481.

35 Zhao L, Fletcher S, Weaver C, Leonardi-Bee J, May J, Fox S, et al: Effects of aspirin, clopidogrel and dipyridamole administered singly and in combination on platelet and leucocyte function in normal volunteers and patients with prior ischaemic stroke. Thromb Haemost 2005;93:527-534.

36 Serebruany VL, Malinin AI, Pokov AN, Hanley DF: Antiplatelet profiles of the fixed-dose combination of extended-release dipyridamole and low-dose aspirin compared with clopidogrel with or without aspirin in patients with type 2 diabetes and a history of transient ischemic attack: a randomized, single-blind, 30-day trial. Clin Ther 2008;30:249-259.

37 Geraghty OC, Paul NL, Chandratheva A, Rothwell PM: Low risk of rebound events after a short course of clopidogrel in acute TIA or minor stroke. Neurology 2010;74:18911896.

38 Sanofi: COMbination of Clopidogrel and Aspirin for Prevention of Early Recurrence in Acute Atherothrombotic Stroke (COMPRESS). ClinicalTrials.gov. http://clinicaltrials.gov/show/ NCT00814268 (first received December 23, 2008).

39 University of California, San Francisco: Platelet-Oriented Inhibition in New TIA and Minor Ischemic Stroke (POINT) Trial. ClinicalTrials.gov. http://clinicaltrials.gov/ct2/show/ NCT00991029 (first received October 6, 2009).
40 Bhatt DL, Fox KA, Hacke W, Berger PB, Black $\mathrm{HR}$, Boden WE, et al: Clopidogrel and aspirin versus aspirin alone for the prevention of atherothrombotic events. N Engl J Med 2006; 354:1706-1717.

41 Gaciong Z: [Clopidogrel and aspirin versus aspirin alone in prevention of atherothrombotic events. The results of CHARISMA study]. Kardiol Pol 2006;64:548-551; discussion 551-552.

42 Palacio S, Hart RG, Pearce LA, Anderson DC, Sharma M, Birnbaum LA, et al: Effect of addition of clopidogrel to aspirin on stroke incidence: meta-analysis of randomized trials. Int J Stroke 2013, DOI: 10.1111/ijs.12050.

43 Huang Y, Li M, Li JY, Li M, Xia YP, Mao L, et al: The efficacy and adverse reaction of bleeding of clopidogrel plus aspirin as compared to aspirin alone after stroke or TIA: a systematic review. PLoS One 2013;8:e65754.

44 Geeganage CM, Diener HC, Algra A, Chen C, Topol EJ, Dengler R, et al: Dual or mono antiplatelet therapy for patients with acute ischemic stroke or transient ischemic attack: systematic review and meta-analysis of randomized controlled trials. Stroke 2012;43: 1058-1066.

45 Wong KS, Wang Y, Leng X, Mao C, Tang J Bath PM, et al: Early dual versus mono antiplatelet therapy for acute non-cardioembolic ischemic stroke or transient ischemic attack: an updated systematic review and meta-analysis. Circulation 2013;128:1656-1666.

-46 Li X, Zhou G, Zhou X, Zhou S: The efficacy and safety of aspirin plus dipyridamole versus aspirin in secondary prevention following TIA or stroke: a meta-analysis of randomized controlled trials. J Neurol Sci 2013;332:9296.

47 Martens RJ, Vink H, van Oostenbrugge RJ, Staals J: Sublingual microvascular glycocalyx dimensions in lacunar stroke patients. Cerebrovasc Dis 2013;35:451-454.

48 Lavallée PC, Labreuche J, Faille D, Huisse MG, Nicaise-Roland P, Dehoux M, et al: Circulating markers of endothelial dysfunction and platelet activation in patients with severe symptomatic cerebral small vessel disease. Cerebrovasc Dis 2013;36:131-138. 


\section{Erratum}

In the article by Zhang et al., entitled 'Aspirin plus Clopidogrel as Secondary Prevention after Stroke or Transient Ischemic Attack: A Systematic Review and Meta-Analysis' [Cerebrovasc Dis 2015;39:13-22, DOI: 10.1159/000369778] there are several errors in the published version. The corrections are as follows:

1. In the original article there is a mix-up of figures. The correct figs. 2-6 with the corresponding legends are printed below.

2. In fig. 5 'Comparison of aspirin and clopidogrel versus aspirin or clopidogrel alone on stroke, MI, or vascular death', 19th line, '( $p=0.057)$ ' should be '( $p=0.37)$ '.

3. On p. 18 , left column, 12 th line, ' $p=0.15$ ' should be ' $\mathrm{p}=0.16$ '.

4. On p. 18, right column, 13th line, '(fig. 5)' should be '(fig. 6)'.

5. On p. 18, right column, 18 th line, ' $0.84-1.03$ ' should be'0.84-1.01'.

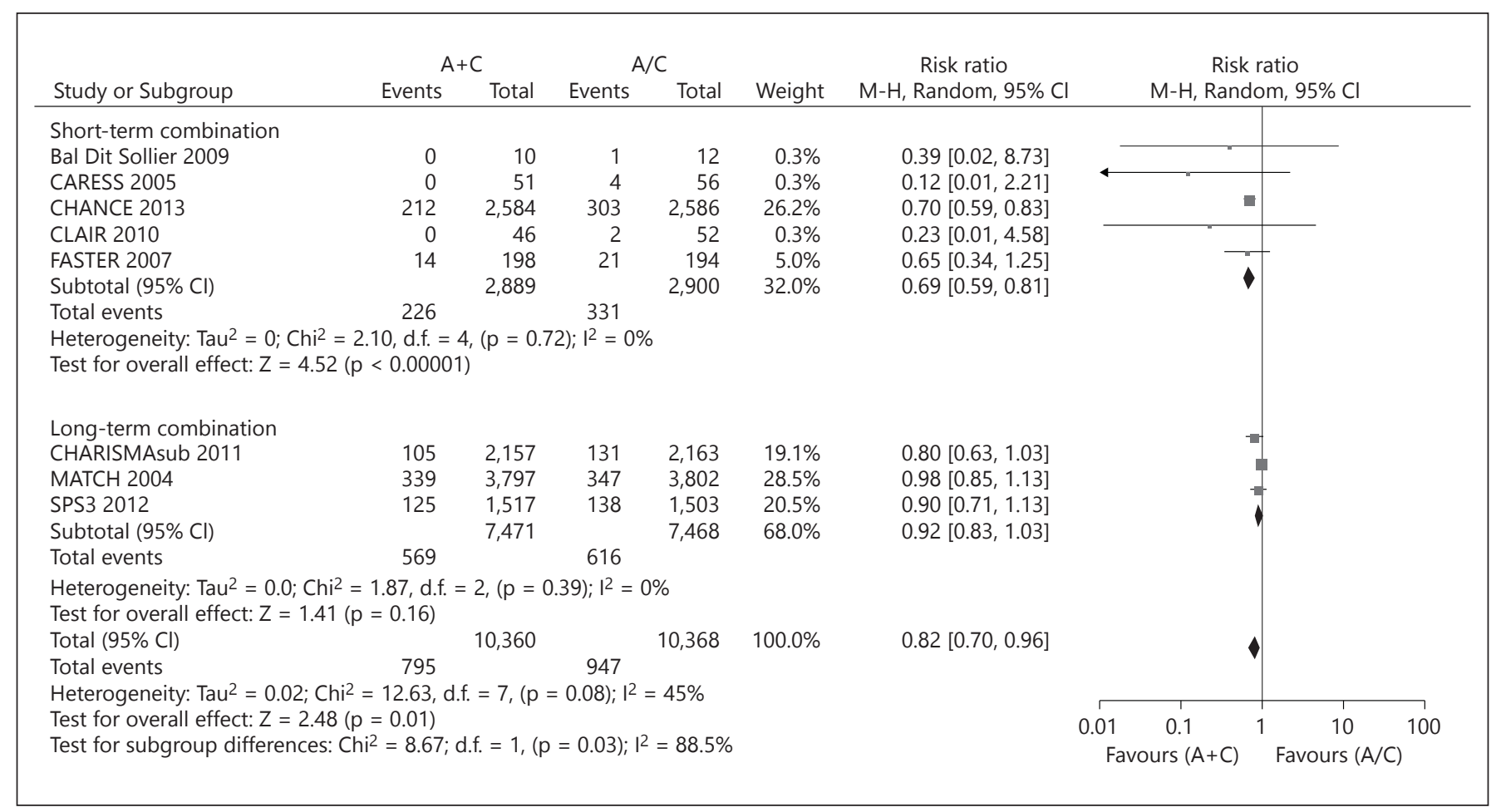

Fig. 2. Comparison of aspirin and clopidogrel versus aspirin or clopidogrel alone on stroke. 


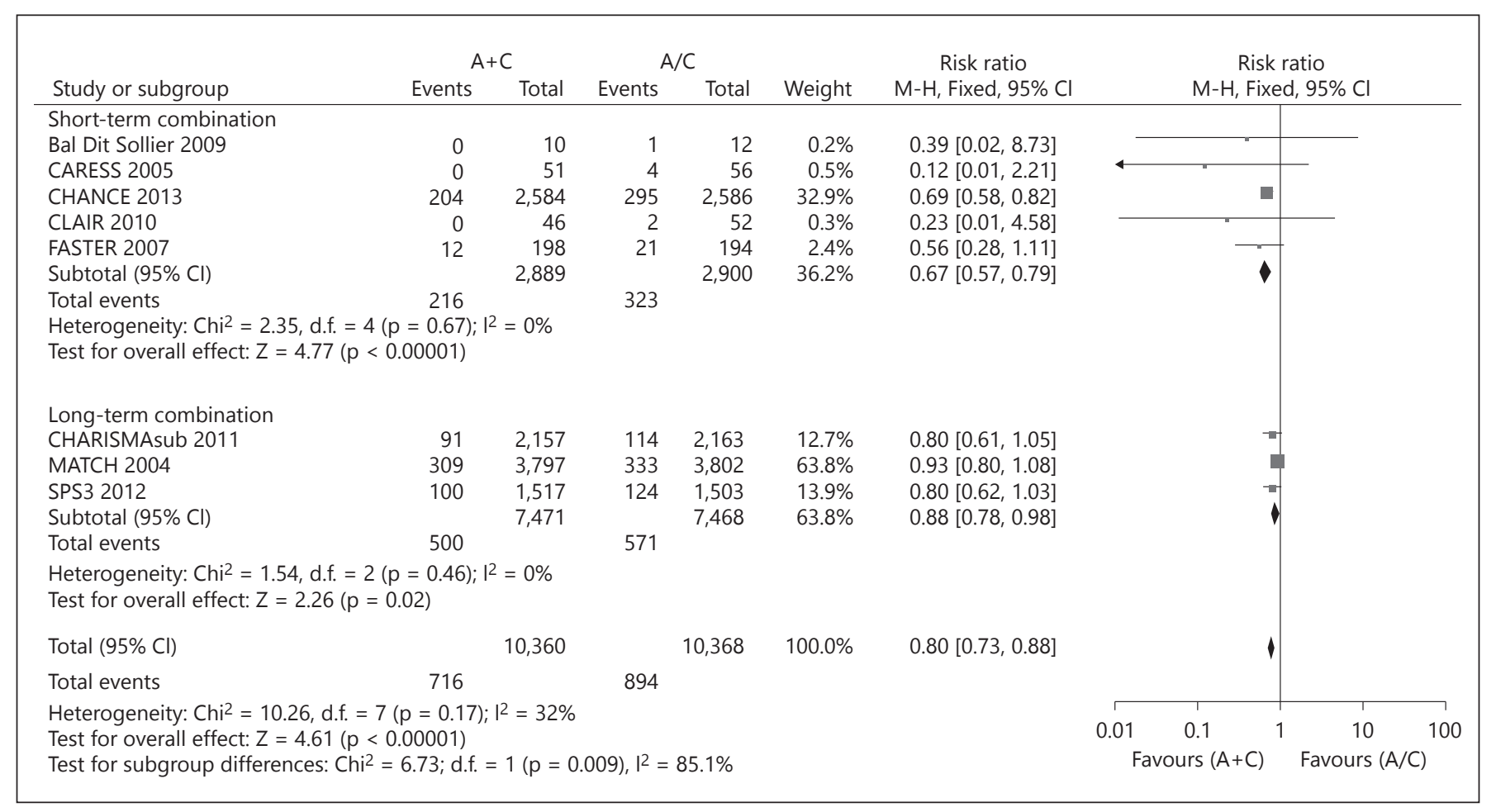

Fig. 3. Comparison of aspirin and clopidogrel versus aspirin or clopidogrel alone on ischemic stroke.

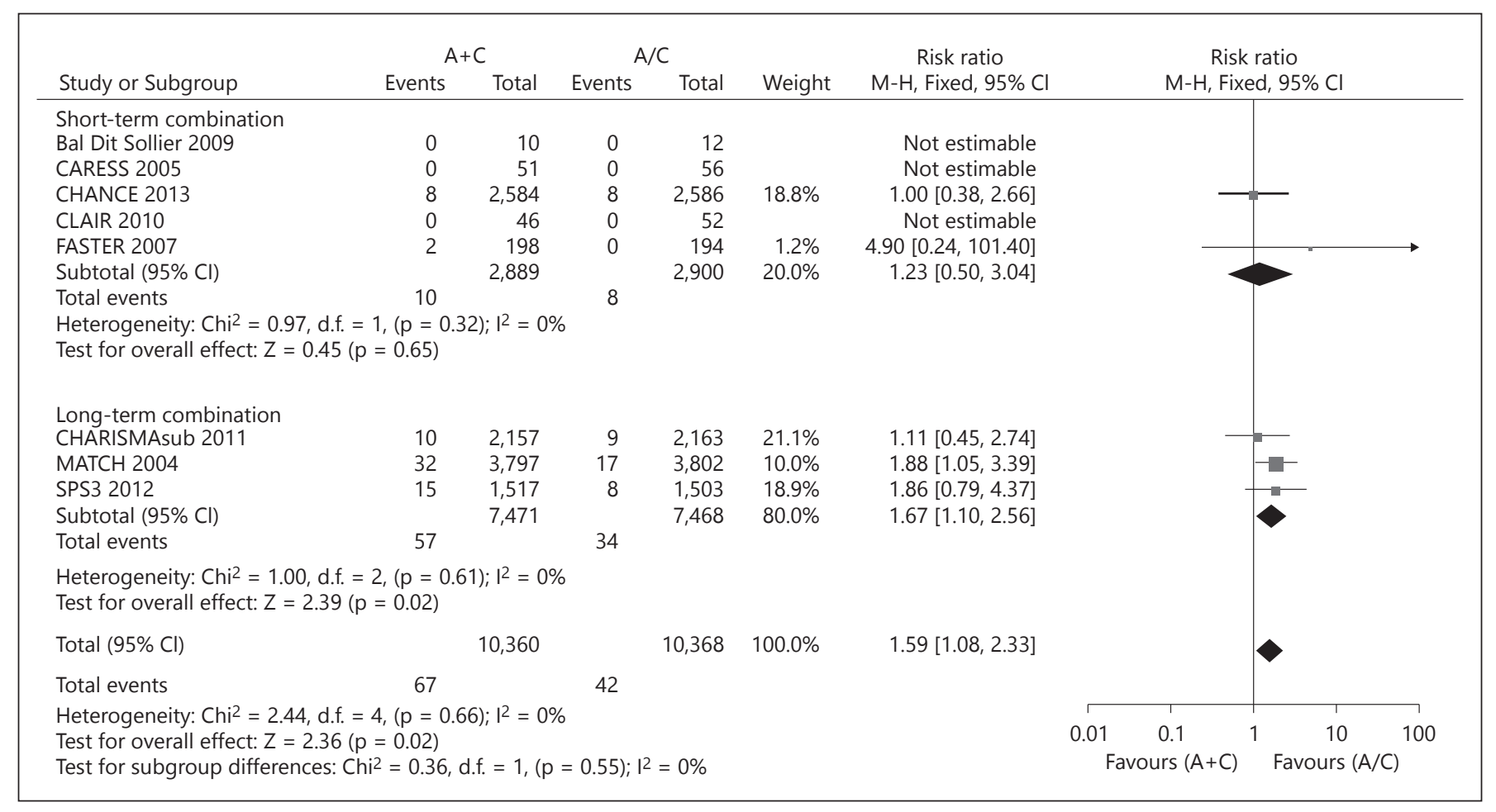

Fig. 4. Comparison of aspirin and clopidogrel versus aspirin or clopidogrel alone on hemorrhagic stroke. 


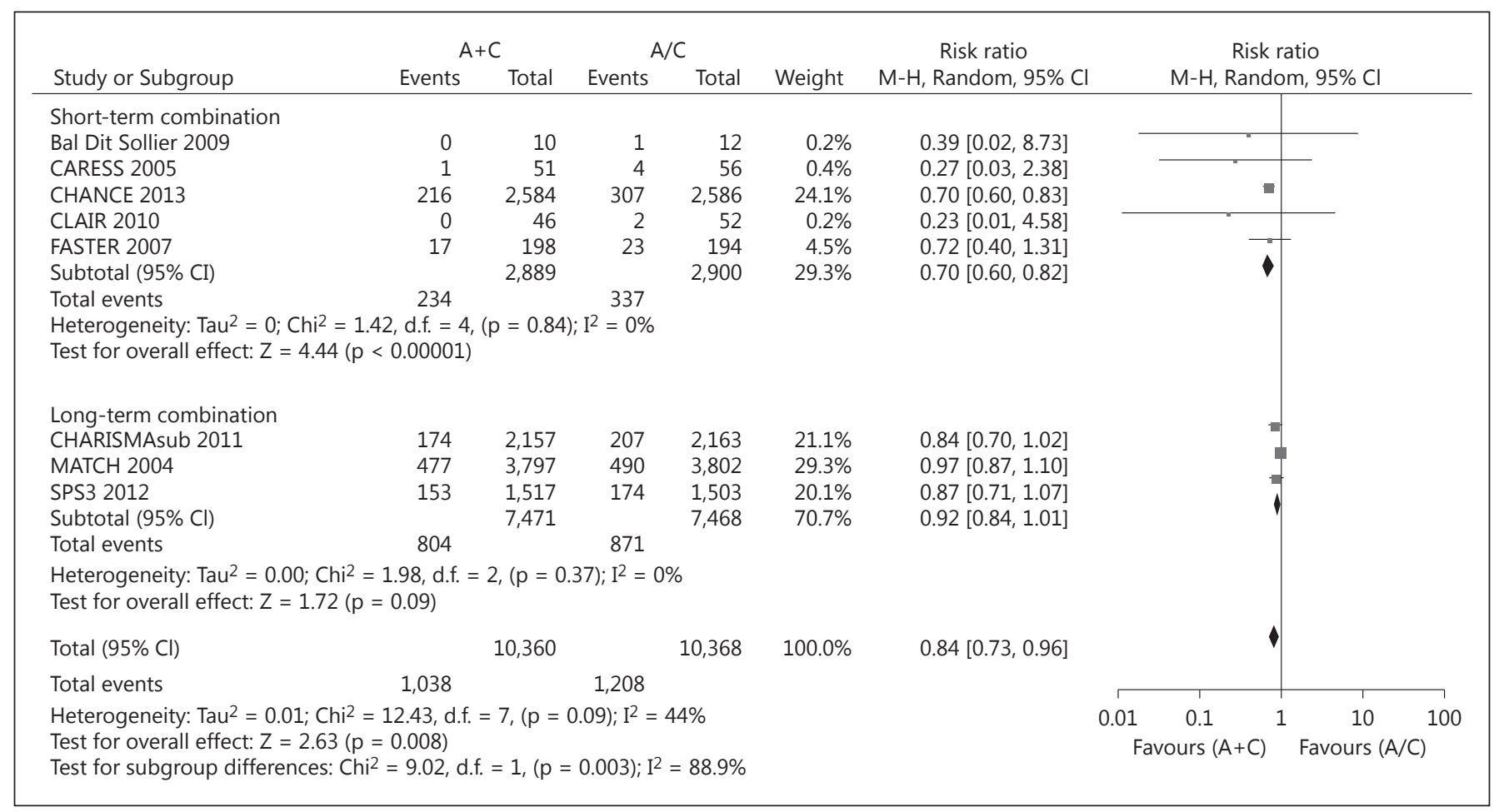

Fig. 5. Comparison of aspirin and clopidogrel versus aspirin or clopidogrel alone on stroke, MI, or vascular death.

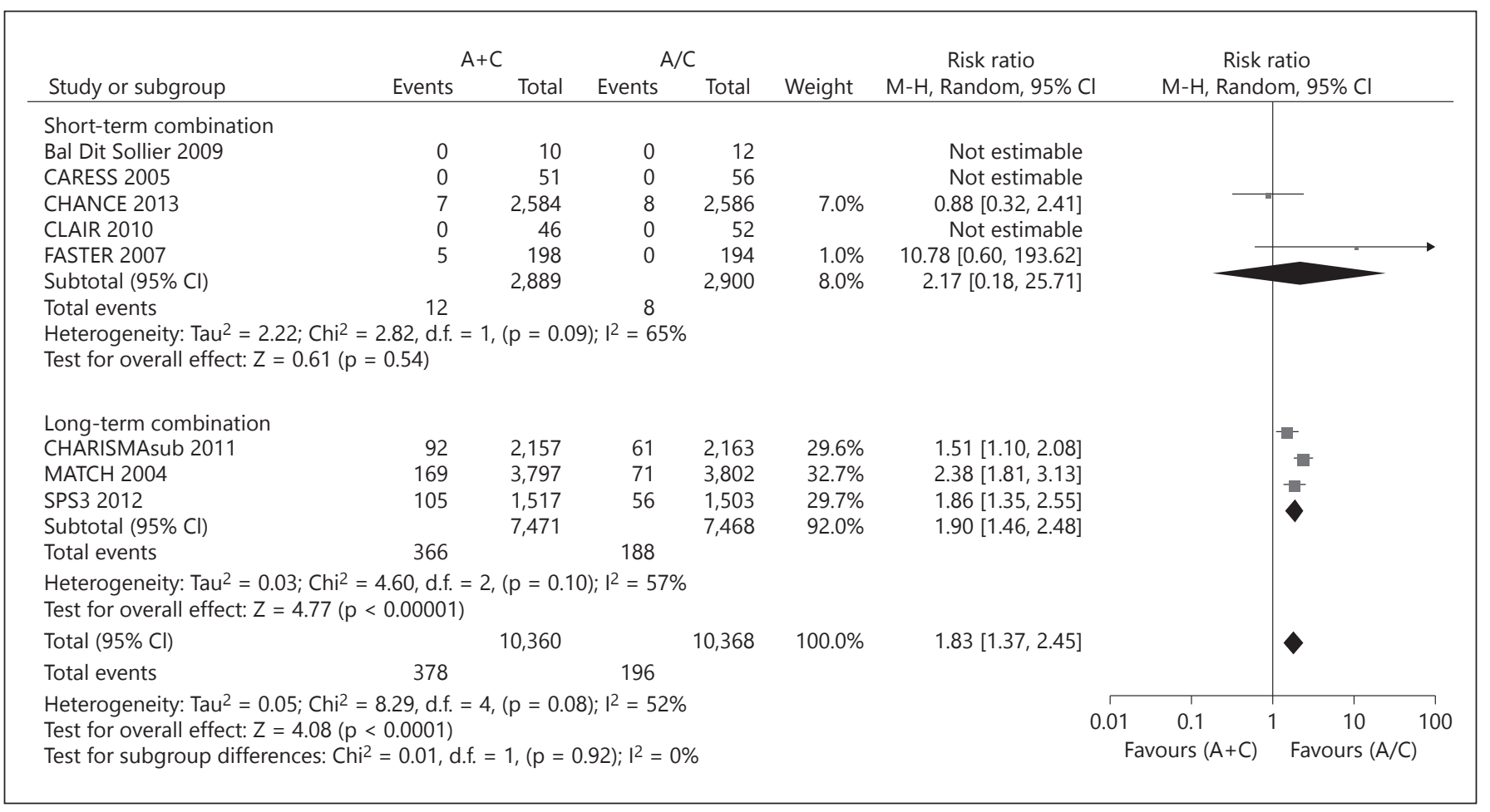

Fig. 6. Comparison of aspirin and clopidogrel versus aspirin or clopidogrel alone on major bleeding. 